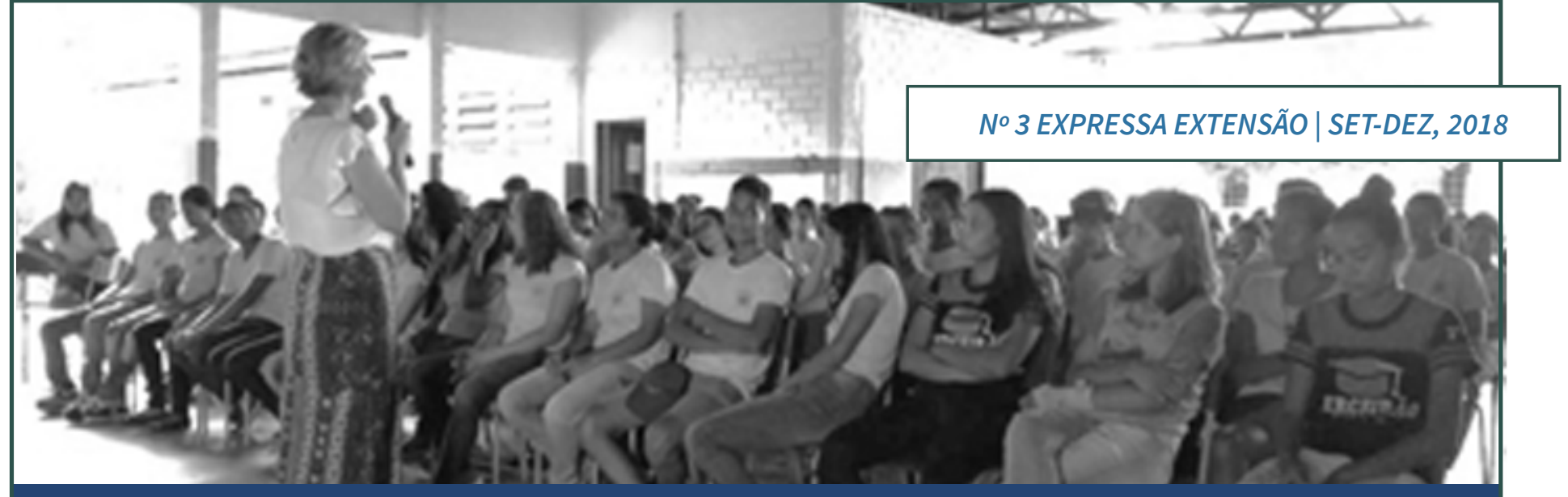

\title{
A NECESSIDADE DE INTERAÇÃO UNIVERSIDADE-ESCOLA: UM ESTUDO DA UNIFESSPA
}

A NECESSARY UNIVERSITY-SCHOOL INTERACTION: A UNIFESSPA STUDY

Manoella Gonçalves Bazzo ${ }^{1}$ Maria Elizabete Rambo Kochhann²

\section{RESUMO}

Este relato apresenta considerações sobre o desenvolvimento de um projeto de divulgação da Universidade Federal do Sul e Sudeste do Pará (Unifesspa) e do Novo Enem. O objetivo foiapresentar aos alunos das escolas da rede pública de municípios dos estados do Pará e Mato Grosso os cursos de graduação da Universidade e de outras instituições presentes na região sudeste do Pará, bem como socializar as particularidades do Exame Nacional do Ensino Médio (ENEM), o Novo Enem, no tocante à Teoria de Resposta ao Item (TRI) e como são construídos os critérios para uma boa redação. A motivação inicial partiu do desejo de ver mais estudantes aproveitarem a oportunidade de frequentar uma Universidade Federal no interior do estadodo Pará. A metodologia consistiu em visitas às escolas da rede pública, com três momentos de encontros com os alunos; o primeiro momento consistia em apresentar o ENEM e a Universidade; o segundo contava com a realização de palestras motivacionais e o terceiro, que é o foco desse relato, eram encontros para explicar a metodologia do ENEM. Observa-se ainda que poucos alunos da educação básica conhecem os critérios de acesso ao ensino superior nessa região do país, bem como há pouca interação da universidade com as escolas locais. Constata-se, portanto, a importância de se realizar ações visando aproximar esse público à universidade.

Palavras-chave: Alunos da educação básica. Avaliação em Larga Escala (ALE). UNIFESSPA. Novo Enem.

\footnotetext{
${ }^{1}$ Universidade Federal de Goiás - Universidade Federal do Sul e Sudeste do Pará - Brasil - Mestranda em Estudos Linguísticos na Universidade Federal de Goiás. Técnica Administrativa em Educação da UNIFESSPA no Instituto de Engenharia do Araguaia - lunnakroty@gmail.com; ${ }^{2}$ Universidade Federal do Sul e Sudeste do Pará - Brasil - Professora Doutora do Programa de Pós-Graduação Stricto Sensu - PPGECM - Universidade do Estado de Mato Grosso, e Docente da Unifesspa no Instituto de Engenharia do Araguaia - beterambo@gmail.com
} 


\section{ABSTRACT}

This article presents considerations about the development of a dissemination project of the Federal University of the South and Southeastof Pará (Unifesspa) andthe New Enem. The objective was to present to the students of the public schools in cities of th estates of Pará and Mato Grosso, the undergraduate courses of the University and other institutions presents in the south east region of Pará, as well as to socialize the particularities of the National High School Examination (NHSE), the New Enem, regarding the Item Response Theory (TRI) and how the criteria for goodwriting are constructed. The initial motivation came from the desire to see more students take the opportunity to attend a Federal University in the country side of the state of Pará. The methodology consisted of visits to the schools of the public network, with three moments of meetings with the students; the first moment consisted in presenting the ENEM and the University; the second counted on motivational lectures and the third, which is the focus of this report, were meetings to explain the ENEM methodology. It is also observed that few students of basic education know the criteria of access to higher education in this region of the country, as well as there is little interaction between the university and local schools. Therefore, it is important to carry out action saimed to bring that public to the university.

Keywords: Students of basic education. Large Scale Evaluation (ALE). UNIFESSPA. New Enem.

\section{INTRODUÇÃO}

Nesse relato apresentamos considerações advindas de ações de divulgação da Universidade Federal do Sul e Sudeste do Pará (Unifesspa) e dos cursos de graduação oferecidos pela universidadee demais instituições públicas de ensino superior presentes nas regiões sul e sudeste desse estado.

Nessas duas regiões do Pará encontram-se instalados vários campiuniversitários: a Unifesspa - presente nos municípios de Marabá (sede), Rondon do Pará, Xinguara, São Félix do Xingu e de Santana do Araguaia; a Universidade Federal Rural da Amazônia (UFRA); o Instituto Federal do Pará(IFPA) e a Universidade do Estado do Pará (UEPA), os quais ofertam diferentes cursos superiores em suas faculdades.

Em Santana do Araguaia, o campus conta, atualmente, com o Instituto de Engenharia do Araguaia (IEA), o qual iniciou suas atividades no ano de 2014, ofertando o curso de Licenciatura em Matemática, com a finalidade de atender a demanda de professores do município de Santana e da região nessa área. Além disso, o campus subsidia a oferta de cursos de Licenciaturas em Matemática e 
Letras pelo Programa Nacional de Formação de Professores da Educação Básica (Parfor), e oferta também o curso de Engenharia Civil. São os servidores desse instituto, em parceria com os acadêmicos, por meio do projeto "A Unifesspa está aí!", que estão promovendo ações cujo objetivo é divulgar os cursos das IES supracitadasnas escolas públicas da região.

O projeto de extensão “A Unifesspa está aí!", sem financiamento externo, iniciado em maio de 2017, com atuação prevista para dois anos, traz como um de seus objetivos a apresentação das instituições de ensino superior e técnico aos estudantes do ensino médio das escolas da região por meio de encontros de divulgação, propondo uma maior interação entre a universidade e as escolas da região.

Tal divulgação dos cursos das instituições para a comunidade escolar é uma das solicitações das instituições parceiras do projeto. Concomitante a essa ação, ocorria uma apresentação aos estudantes do nível médio de uma das Avaliações em Larga Escala (ALE) realizadas no Brasil, mais especificamente, o Exame Nacional do Ensino Médio (ENEM), e sua atual configuração, baseada na Teoria de Resposta ao Item (TRI).

O ENEM, criado em 1998, tem como objetivo avaliar o desempenho do estudante ao término da educação básica, buscando contribuir para a melhoria da qualidade desse nível de escolaridade (BRASIL, [200_?]). No site do Ministério da Educação (MEC) é possível obter mais informações a respeito desse exame que, a partir de 2009, passou a ser utilizado também como mecanismo de seleção para o ingresso no ensino superior.

Ressalte-se, ainda, que foramimplementadas mudanças que contribuem para a democratização das oportunidades de acesso às vagas oferecidas por Instituições Federais de Ensino Superior (IFES), no que diz respeito à mobilidade acadêmica e à reestruturação dos currículos do ensino médio (BRASIL, [201_]).

Assim é que construímos este relato com a seguinte configuração: esta introdução; o referencial teórico no qual nos embasamos, mostrando estudiosos que discorrem sobre as ALEs, o ENEM, e também um pouco sobre o projeto "A Unifesspa está aí!", considerando-se a política pública que o envolve; a metodologia que se desenvolveu na realização das ações, caracterizando-se inicialmente os lugares onde foram empreendidas; os resultados; as conclusões e as referências bibliográficas. 


\section{DISCUSSÕES TEÓRICAS}

Ao discorrer sobre a Avaliação em Larga Escala (ALE) no sistema educacional brasileiro, Werle (2011) afirma que a mesma é uma proposta com origem na instância federal, nos estados da nação, em alguns municípios e também em outros países. Uma proposta que teve início na década de 80 , quando o MEC, incentivado por agências financiadoras, ao iniciar estudos concernentes à avaliação educacional, construiu as bases de uma política que, posteriormente, deu origem ao Sistema de Avaliação da Educação Básica (SAEB).

Sousa (2011, p. 311) afirma que as Avaliações em Larga Escala, "[...] com provas padronizadas, apesar de trazerem informações que usualmente possibilitam a comparabilidade de desempenho dos alunos, não dão conta da amplitude e complexidade do trabalho escolar." Como exemplo, não denota o desenvolvimento de atitudes.

Ainda em Sousa, encontra-se:

[...] dependendo do modo como forem divulgados e explorados os resultados das avaliações em larga escala, corre-se o risco de se intensificar desigualdades educacionais, com impactos na segmentação de professores e escolas. Daí deve-se atentar para não utilizar os resultados com fins classificatórios. Não se pode restringir a concepção de qualidade do ensino aos resultados dessas avaliações, correndo-se o risco de não se diferenciar as noções de medida e avaliação, além de fragilizar a perspectiva de uma avaliação formativa (SOUSA, 2011, p.311).

Especificamente sobre o ENEM, Werle(2011) ressalta que o exame foi, inicialmente,

recebido com descrédito por parte das Universidades, e com reações contrárias, inclusive por parte dos estudantes. Uma das dificuldades era o pagamento de taxas para sua realização, frente ao que algumas secretarias de educação se dispuseram a arcar com os custos de inscrição dos estudantes das escolas públicas (WERLE, 2011, p. 776).

Contudo, afirma que o mesmo foi, aos poucos, conseguindo espaço e força em decorrência de três eixos de questões, quais sejam:

Primeiro, com a adesão de Universidades que passaram a considerar os resultados obtidos pelos estudantes para o ingresso no Ensino Superior, em segundo lugar, com o Programa Universidade para Todos (ProUni) cujo critério de ingresso no Ensino Superior apenas considera os resultados do Enem e, em terceiro lugar, com a implantação do Sistema de Seleção Unificada (Sisu) (WERLE, 2011, p. 776).

Assim, em 2009, o Ministério da Educação apresentou uma proposta de reformulação do ENEM e sua utilização como forma de seleção unificada nos processos seletivos das universidades públicas federais, o Novo Enem. E para que 
essa nova proposta fosse de conhecimento dos alunos da rede pública das escolas parceiras doprojeto “A Unifesspa está aí!”, foi realizada uma ação de divulgação da mesma, empreendida por um grupo de servidores do IEA da Unifesspa - Campus de Santana do Araguaia - PA, os quais são também pesquisadores desse projeto.

A respeito doprojeto,o qual foi submetido e aprovado nocolegiadodo Instituto, verifica-se que o mesmo apresenta como principal objetivo difundir o nome da universidade e seus cursos na região, como forma de atrair novos alunos, tornando a Unifesspa um espaço conhecido e convidativo para o acesso à educação superior, além de estreitar a parceria entre a universidade e as escolas buscando contribuir com os estudantes e seus professores na inovação, na descoberta, na curiosidade, no fazer ciência e no uso avançado das tecnologias de informação e comunicação, criando espaços para a chamada geração $Y$ desenvolver novas competências básicas para a sua sobrevivência, pensar e construir projetos próprios e altamente críticos em relação aos que existem na sociedade atual.

O projeto está dividido em três etapas, sendo que a primeira inclui palestras de divulgação das inscrições do ENEM, a fim de incentivar os estudantes da educação básica a buscarem o crescimento profissional através dos cursos de graduação; a segunda prevê palestras motivacionais nas mesmas turmas e escolas visitadas, a fim de motivar os estudantes, permitindo que busquem ampliar sua formação com a ascensão ao ensino superior.

A ação que comentamos nesse artigo se refere à terceira etapa do projeto, em que há a preocupação de trabalhar a temática do ENEM e dos critérios de correção da redação dos estudantes do ensino médio que fizerem o exame.

Na compreensão dos diretores das escolas parceiras do projeto "A Unifesspa está aí!”, os resultados do desempenho dos estudantes dessas unidades, nas ALEs, mostraram-se críticos ou muito críticos, considerando-se os índices da região Norte e também sua comparação em nível nacional. Essa realidade pode ser constatada pessoalmente por meio da presença de servidores e acadêmicos do curso de Licenciatura em Matemática dentro dos espaços escolares, seja por meio de realização dos vários projetos de extensão desenvolvidos seja pela realização de estágios curriculares.

Assim, além de divulgar os cursos existentes nas IES presentes nas regiões sul e sudeste do Pará, a equipe do IEA da Unifesspa propôs ações para que os alunos do ensino médio pudessem conhecer a estrutura do Novo ENEM, com enfoque aos critérios de avaliação. Tais critérios, desde o ano de 2005, compreendem o sistema de correção baseado na Teoria de Resposta ao Item, também denominada de TRI. Essa teoria tem por característica superar algumas limitações evidenciadas na sua antecessora, ou seja, a Teoria Clássica do Teste (TCT). 
Nessa nova teoria, identifica-se a habilidade do aluno não só pela quantidade de acertos, mas sim, pelo seu padrão de escolha entre acertos e erros, o chamado padrão de resposta do aluno. Na TRI, as análises do padrão de resposta estão fundamentadas no método logístico, que estima para um padrão de resposta a sua respectiva habilidade, ou aquilo que na psicometria se conhece por Traço Latente.

Comentamos mais especificamente sobre o modo como ocorreram tais divulgações nas escolas dos municípios atendidos no item subsequente.

\section{DISCUSSÕES E RESULTADOS}

Antes de discutirmos as atividades realizadas, apresentamos, sucintamente, os lugares onde ocorreu a divulgação dos cursos da Unifesspa e do Novo ENEM.

Figura 1 - Mapa - Mesorregião do Sudeste Paraense

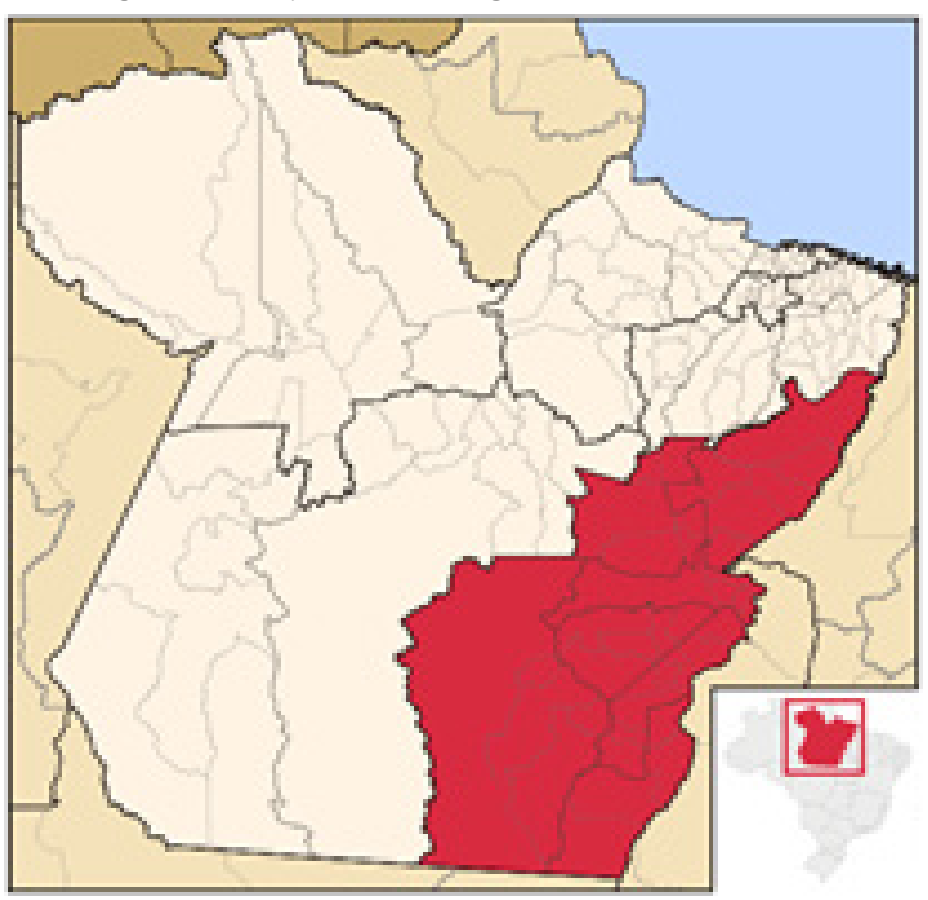

Fonte: Wikipédia

A Unifesspa é uma universidade localizada no interior do Estado do Pará, atendendo a maioria dos municípios das regiōes sul e sudeste (Mesorregião Sudeste Paraense), conforme se observa na Figura 1. 
O principal compromisso da Unifesspa é:

possibilitar aos estudantes da região acesso à educação superior pública de qualidade, sem imperativo deslocamento para grandes centros, ensejando a fixação de profissionais qualificados, em cumprimento à função social das universidades públicas, especialmente na Amazônia (UNIFESSPA, 2013).

Dessa forma, atua na qualificação e formação em nível superior em diversas especialidades, envolvendo39 municípios nasregiōes sul e sudeste paraense, com alcance no norte do Tocantins, sul do Maranhão e norte do Mato Grosso (UNIFESSPA, 2013). No Campus de Santana do Araguaiasão ofertados os cursos de Licenciatura em Matemática e de Engenharia Civil, além de turmas do Parfor - Licenciatura em Matemática e em Língua Portuguesa.

O município de Santana do Araguaia pertence à Mesorregião Sudeste Paraense e à Microrregião Conceição do Araguaia. Traz como limite ao norte o município de Santa Maria das Barreiras; aleste, o Estado do Tocantins; ao sul, o Estado do Mato Grosso e aoeste os municípios de São Félix do Xingu e Cumaru do Norte (FAPESPA, 2016). Possui uma população estimada de 70.764 habitantes, conforme os dados do Instituto Brasileiro de Geografia e Estatística (IBGE) de 2017.

O Projeto "A Unifesspa está aí!" contou, como instituições parceiras, com asescolas localizadas nesse município e nos municípios de Redenção (PA), Santa Maria das Barreiras (PA) e Vila Rica (MT) no ano de 2017, e para o ano de 2018 sua abrangência será ampliada, alcançando novos municípios nesses estados e a inclusão de municípios no estado do Tocantins.

Durante o ano de 2017, a equipe do projeto percorreu esses municípios visitando as escolas que ofertam o ensino médio, iniciando com a solicitação de uma autorização à direção de cada unidade e, posteriormente, após essa autorização, reunia as turmas do $3^{\circ}$ ano em algum espaço da escola, como pode ser verificado na Figura 2 , onde ocorriam as atividades das $1^{\mathrm{a}}$ e $2^{\mathrm{a}}$ etapas do projeto. A apresentação do grupo ocorria por meio de uma exposição oral, mostrando os cursos ofertados pela Unifesspa e demais universidades presentes na região, anteriormente citadas. 
Figura 2 - Realização da $1^{a}$ etapa do projeto numa escola no município de Redenção/PA

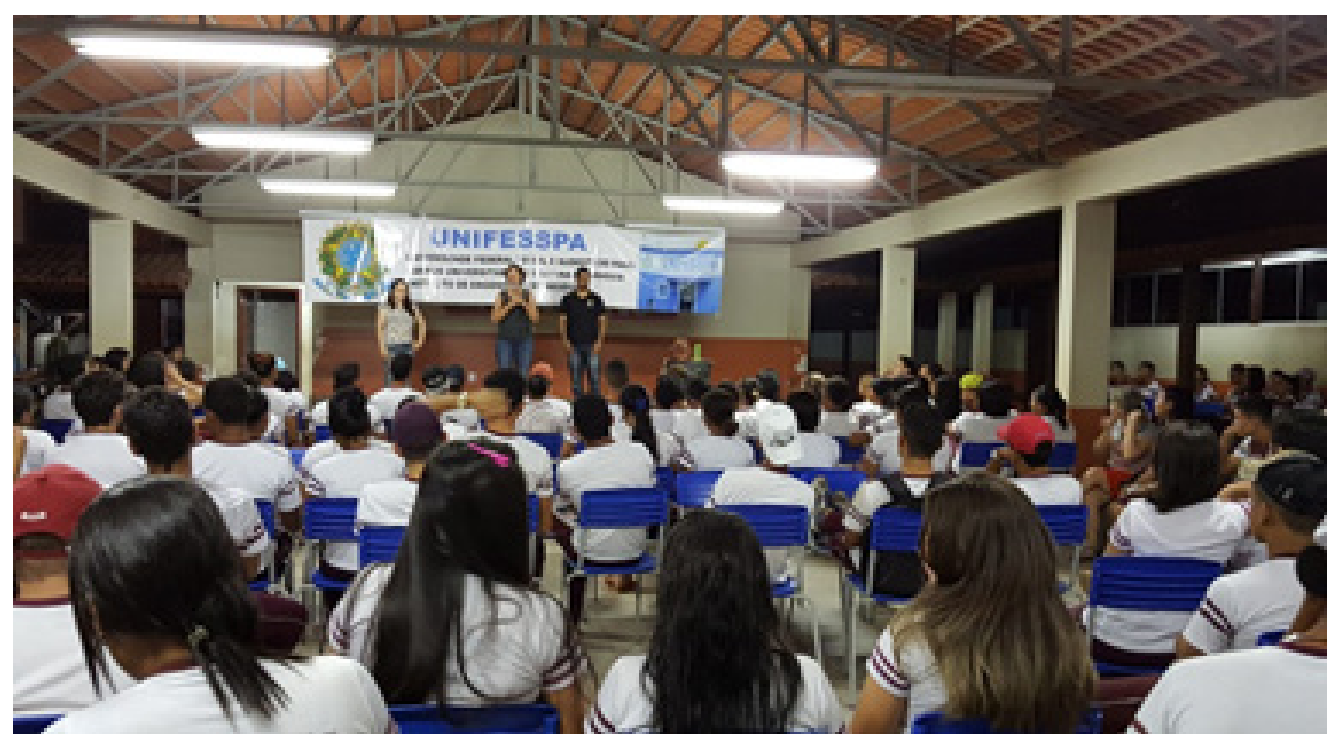

Fonte: Acervo do projeto

Após esse primeiro momento, foram socializados os programas de apoio que as universidades possuem atualmente, quais sejam, as bolsas: Auxílio Alimentação, Moradia, Iniciação Científica, Monitoria, Tutoria e outras;o que causou surpresa nos estudantes em saber que, ao ingressarem em um desses cursos, poderão ser contemplados com tais auxílios durante seus estudos.

Na terceira etapa do projeto, a palestra iniciava com a seguinte pergunta: “Quem de vocês fará o ENEM este ano?”. E para a surpresa do grupo, verificou-se que nem todos os alunos realizariam a prova, desconhecendo-se os motivos de tal opção. Com o diálogo desenvolvido, notamos que muitos estudantes não tinham conhecimento das IES na região, nem dos cursos ofertados por essas. Para alertá-los sobre o novo método de avaliação do ENEM, com o intuito de maximizar as notas alcançadas nesse exame, era necessário que os mesmos conhecessem a TRI. E para introduzir o conceito de correção logística utilizado pela teoria, foi realizado em todas as turmas um problema seguido de uma pergunta, desta forma: "Se a prova do Enem tivesse 10 questões, 05 fáceis e 05 difíceis, em que o aluno A acertasse as 05 questões fáceis, e o aluno Bacertasse as 05 questões difíceis, quem teria a maior nota: o aluno A ou aluno B? Para a referida pergunta, obteve-se basicamente três tipos de respostas, são elas:

R 1 -O aluno B terá maior nota, pois as questões difíceis têm maior peso;

R 2 -A mesma nota, pois ambos acertaram 05 questões;

R 3 - O aluno A, pois o aluno não pode acertar questões difíceis errando questões fáceis. 
Após breves discussões sobre o assunto "maior nota", revelou-se para os alunos duas grandes verdades até então desconhecidas da maioria dos participantes das palestras. Verdade 1: o aluno B terá maior nota, possivelmente bem superior ao aluno A; verdade 2: na TRI não existe peso para questão difícil, ou seja, as questões difíceis não estão associadas às questões que têm maior peso.

Ambas as revelações trouxeram grandes impactos para os estudantes na compreensão de como tirar boas notas no ENEM, pois elas não estão associadas à quantidade de que, quanto mais questões difíceis o aluno acertar, maior será a sua nota, mas sim, na quantidade de questões fáceis que errará, uma vez que o método logístico da TRI é o conhecimento ser acumulativo, ou seja, para saber questões difíceis, o aluno deve saber questões fáceis. Dito de outra forma, ao se realizar escala de habilidades, espera-se que aqueles alunos com grandes índices de habilidades tenham todo conhecimento dos níveis de habilidades anteriores. Sendo assim, a TRI revela que, para o aluno acertar questões difíceis, é necessário que seu conhecimento nas questões fáceis seja alto.

Figura 3 - Realização da $3^{\text {a }}$ etapa do projeto numa escola no município de Santana do Araguaia/PA

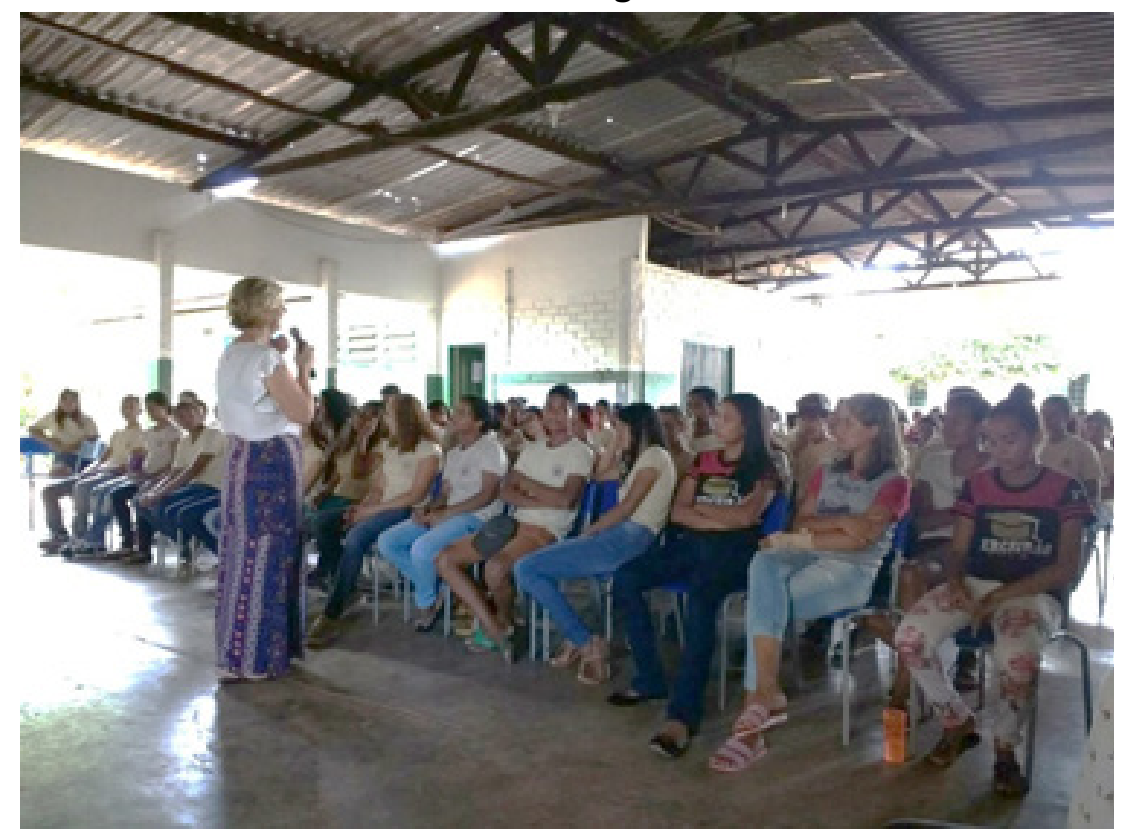

Fonte: Acervo do projeto

Durante essa ação, percebeu-se o interesse dos alunos em compreender o processo para o ingresso no nível superior, sendo que alguns procuraram a equipe para maiores esclarecimentos ao final da palestra. Essa dinâmica ocorreu em todas as escolas de nível médio na regiãode alcance do projeto, e também nos outros municípios próximos a ela. Os resultados dessa intervenção são comentados no item seguinte. 


\section{RESULTADOS}

Como resultado dessa açãoesperávamos que a procura por cursos dessa IES, particularmente no Campus de Santana do Araguaia,fosse maior que a média das últimas edições do ENEM. Contudo, após análise e comparação dos dados do Sistema de Seleção Unificada (Sisu) 2017.1 e 2018.1, percebemos que a quantidade de interesse de matrícula de 530 caiu para 410, respectivamente.

Apesar disso, um resultado muito positivo que obtivemos foi o aumento do interesse e a procura de alunos do próprio município pelos cursos ofertados, o que representa o maior ganho da ação executada através do projeto. A turma de 2018 fechou com vinte e três alunos matriculados e cursando, sendo a maioria ex-alunos da rede pública estadual de Santana do Araguaia e distritos. Outro ponto positivo do projeto foi a maior interação que aconteceu entre a universidade e as escolas, o que em nosso entendimento, contribui para despertar nos alunos do Ensino Médio o desejo de cursar o ensino superior. A visualização de novos referenciais é necessária para ajudar a criar novos objetivos para esses educandos, que podem sonhar e buscar a realização de uma formação profissional de qualidade e totalmente gratuita.

Paralelo a isso, o nome da universidade tornou-se mais conhecido na região, bem como os cursos ofertados por ela. A comunidade em geral, dos quais agentes dos poderes públicos, políticos e lideranças locais demonstraram apoio pelo fortalecimento da universidade, reconhecendo sua importância para o desenvolvimento local e regional. Uma mudança considerável, pois, no início das atividades, a maioria do público atingido não conhecia a instituição e nem sabia de sua presença na localidade. Atualmente, podemos expandir parcerias com a finalidade de contribuirmos juntos para um percurso coletivo de valorização da educação e estímulo para o investimento na formação pessoal.

\section{CONSIDERAÇÕES FINAIS}

A presença da Unifesspa no sudeste paraense atende a uma grande demanda de formação advinda de todas as áreas e sujeitos. Essa demanda torna-se maior à medida que seus campi adentram no interior, cujas demandas sociais, econômicas e políticas são ainda mais exigentes.

Percebemos que o desmembramento da Universidade Federal do Pará (UFPA) em novas universidades, como é o caso da Unifesspa, contribuiu fortemente para a expansão de oferta de cursos e vagas ao nível superior, acolhendo a demanda da realidade local e regional. Contudo, o conhecimento e acesso a esses cursos não acompanhou essa expansão. A partir do contato nas escolas visitadas e parceiras, percebemos que muitos jovens ainda desconheciam boa 
parte dos cursos presentes na região; não sabiam a importância do ENEM para o acesso a esses cursos; ignoravam a diferença que um curso superior poderia trazer para sua vida pessoal e profissional e a diferença entre cursos ofertados em universidades públicas e universidades particulares.

Assim, o que se observou após as primeiras ações realizadas pelo projeto foi, especialmente, a valorização da universidade na região, com consequente estímulo entre os jovens pelo ingresso em cursos superiores. Isso evidencia a importância de se realizarem ações dessa natureza, mas o desafio que se coloca, ainda, é criar espaços para que os alunos se formem em IES com qualidade, a fim de que possam se tornar pessoas com autonomia para a construção de projetos que visem uma sociedade mais justa e igualitária.

Para a continuidade do projeto, algumas propostas estão sendo revistas, como a ampliação da área de atuação, envolvendo novos municípios e realização de subprojetos vinculados a esse projeto maior, com vistas ao fortalecimento das ações já realizadas.

Por fim, queremos ressaltar também que, ao realizarmos tais ações envolvendo a universidade e a educação básica, esperamos estar em consonância com o que preconizam as políticas públicas educacionais no Brasil, no que concerne à realização da Avaliação em Larga Escala, e, especialmente, esperamos contribuir para o maior acesso de jovens ao nível superior, com uma educação de qualidade, que contribua para o desenvolvimento de potencialidades e para a formação qualificada.

\section{REFERÊNCIAS}

BRASIL. Ministério da Educação. Novo Enem.[201_]. Disponível em: <http:// portal.mec.gov.br/busca-geral/179-estudantes-108009469/vestibulares-1723538374/13318-novo-enem>. Acesso em: 18 maio 2018.

Enem: apresentação. [200-?]. Disponível em: <http://portal.mec.gov.br/ enem-sp-2094708791>. Acesso em: 22 maio 2018.

FAPESPA. Estatísticas municipais paraenses: Santana do Araguaia. Belém: Diretoria deEstatística e de Tecnologia e Gestão da Informação, 2016. Disponível em: <http://www.fapespa.pa.gov.br/upload/Arquivo/anexo/1255.pdf?id=1526929793 >. Acesso em: 20 maio 2018.

IBGE. Cidades. [Brasília]: 2017. Disponível em: <https://cidades.ibge.gov.br/brasil/pa/santana-do-araguaia/panorama>. Acesso em: 21 maio 2018. 
SOUSA, S. Z. Avaliações em larga escala e os desafios à qualidade educacional. Roteiro, v. 36, n. 2, p. 309-314, 2011. Disponível em: <http://editora.unoesc.edu. br/index.php/roteiro/article/view/1184>. Acesso em: 27 ago. 2014.

UNIFESSPA (2013). Histórico. Disponível em: <https://www.unifesspa.edu.br/inst/ historico>. Acesso em: 18 maio 2018.

WERLE, Flávia Obino Corrêa. Políticas de avaliação em larga escala na educação básica: do controle de resultados à intervenção nos processos de operacionalização do ensino. Ensaio: Aval. Pol. Públ. Educ., Rio de Janeiro, v. 19, n. 73, p. 769-792, dez.2011. Disponível em:<http://www.scielo.br/scielo.php?script=sci_ arttext\&pid=S0104-40362011000500003\&lng=pt\&nrm=iso >. Acesso em: 21 maio 2018.

Data de recebimento: 27 de junho de 2018.

Data de aceite para publicação: 19 de julho de 2018. 